\title{
Medicolegal storm threatening maternal and child healthcare services
}

South Africa (SA)'s healthcare system is on the cusp of a perfect storm that has the potential to paralyse service delivery, in particular the delivery of maternal and child services. Since about 2008, the number of medicolegal claims brought against both private and public healthcare providers has accelerated. ${ }^{[1,2]}$ Underpinning this is an under-resourced public sector that is lacking in strong management in many parts of the country, a fragmented private sector that has been criticised for lack of accountability, raised patient expectations and increased awareness by patients of their rights, and SA's legislative and dispute resolution framework. This trend, together with the associated increase in the value of individual claims, appears to have coincided with promulgation of the Road Accident Amendment Act No. 19 of 2005, which came into effect in August 2008 and capped claims for those who suffered harm on SA roads. ${ }^{[1-3]}$ Given the significant quantum of potential damages that can be claimed in terms of minors with severe disabilities, there is reason to believe that the high number of claims in relation to supposed birth-related injuries reflects, at least in part, a shift of contingency-based litigation from road accident victims to those harmed on the basis of alleged neglect by the healthcare system (the highest proportion of claims brought against government hospitals relate to birth-related injuries, particularly cerebral palsy). ${ }^{[2,4]}$ Efforts by government to mobilise additional financing and human resources to improve access to quality care in SA are being undermined systematically by claims of medical negligence in both the public and private sectors:

- By mid-2017, contingent liabilities for alleged medical negligence in the public sector reached in excess of ZAR55 billion, excluding legal expenses, which is a significant portion of the health budget (data on file, National Department of Health). The national budget allocated to health in 2016/2017 was ZAR184.217 billion. ${ }^{[5]}$

- Fear of litigation is causing healthcare professionals to practise defensive medicine whereby doctors 'perform additional diagnostic examinations, refer patients to specialists and do follow-up procedures, not for the sake of providing better patient care, but rather to avoid the possibility of being sued. ${ }^{[3]}$ Other than increasing healthcare expenditure unnecessarily, defensive practices are not in the best interests of patient care. ${ }^{[6]}$ In the private sector, defensive practice is often quoted to be contributing significantly to the high caesarean section rate.

- In a recent survey commissioned by the South African Society of Obstetricians and Gynaecologists (SASOG) and distributed to its membership of registered specialists, only $12 \%$ of 201 survey respondents indicated that they would definitely be practising obstetrics in 5 years' time; $21 \%$ of respondents indicated that they were certain to stop. The median response to the question 'How likely are you to stop obstetrics in the next 5 years?' was $75 \%$, meaning that half the cohort was of the view that there was at least a 3 in 4 chance that they would stop obstetrics in the next 5 years. Cost of indemnity insurance, closely followed by the fear and stress of a potential lawsuit, were the predominant reasons cited for these trends (data on file, SASOG). This impending supply-side constraint has access and quality-of-care implications.

\section{The need for multidimensional, collaborative and aligned risk management}

To avert a national crisis and navigate the medical industry into calmer waters, risk management initiatives must focus on minimising adverse clinical outcomes, identifying and managing unfounded claims as early as possible, and settling those with merit fairly, in the most expeditious and cost-effective manner. While the current situation appears dire at face value, various industry initiatives aimed at stabilising the market have taken shape in the past year.

\section{Doctor-driven practice protocols and peer review}

With avoidance of preventable medical error being key to effective risk management, SASOG has devised a programme aimed at promoting safer deliveries and healthier babies. The approach is modelled on the redesign of the patient safety programme by the Hospital Corporation of America in 2000, at a time when the organisation was experiencing similar challenges of inadequate perinatal outcomes and high rates of litigation. By incorporating features of high-reliability industries such as aviation, this large private healthcare delivery system in the USA managed to improve perinatal outcomes and effect a decline in the frequency and quantum of litigation claims. Standardisation of processes and procedures, the development of unambiguous practice guidelines and effective peer review were key to their approach. It was argued that standard protocols had the two-fold effect of guiding good clinical practice as well as providing a benchmark against which practice could be evaluated. In a court of law, it is typically asked in a situation of alleged medical negligence whether specific protocols were followed in a particular situation. In the absence of these, the standard against which the actions of the defendant will be judged is battled out during trial, guided by medical experts introduced by the opposing parties and, in the US context, decided by jury sympathy. Other than adding significantly to legal costs, such an approach is marred by the imperfections of expert witnesses. Regarding peer review, the importance of a robust process to identify gaps in care that did not rely solely on a local committee that could inadvertently be influenced by the economic relationship (partner v. competitor) of one practitioner with another was recognised. To address substandard levels of care, a national peer review committee was appointed to address the most serious cases of adverse outcomes. ${ }^{[7]}$

Based on such an initiative, SASOG has launched the BetterObs programme, which includes the development and publication of practice protocols and the introduction of a structured local and national peer review process. It furthermore encourages attendance at hospital morbidity and mortality meetings and the completion of delivery reports. In the event of disputes, it makes provision for a panel of recognised experts. ${ }^{[8]}$

\section{Informed consent}

Poor communication is a common cause of patient dissatisfaction. Where disputes arise, patients frequently claim that they were not 
informed of the reasons for and limitations of proposed procedures, including common complications (and that had they been informed fully, they would have chosen a different route of care). To encourage improved communication, SASOG, as well as other surgical societies, are reviewing standards for informed consent. While approaches differ per discipline, the emphasis is on encouraging documented patient feedback, for example, specific choice of test for fetal abnormality screening (a tick-box approach) or descriptive feedback of patients' understanding of reasons for surgery, as well as anticipated outcomes.

\section{Conflict resolution}

Litigation as a form of resolving disputes and proclaiming who is right and wrong is not only expensive but time-consuming, emotionally draining and lengthy. It has been estimated that $75 \%$ of medicolegal cases take more than 5 years to be finalised. ${ }^{[3]}$ Wherever possible, and for the benefit of healthcare providers and patients alike, grievances should be settled in a non-adversarial manner outside of the courts. While the South African Law Reform Commission (SALRC) is investigating potential legislative change to facilitate expeditious, fair and cost-effective conflict resolution, the industry is implementing practical changes aimed at promoting the former. A so-called premediation clause whereby patients agree to a confidential and 'without prejudice' meeting to explore the benefits of mediation prior to taking legal action is increasingly forming part of a signed contract between healthcare providers (private hospitals as well as doctors) and patients. Mediation is a process facilitated by an independent, trained person, aimed at seeking win-win solutions between opposing entities and taking into consideration their respective needs, interests and concerns. To protect the delivery of quality care, the SALRC is furthermore researching other judicial risk management solutions relating to contingency-based litigation, the common-law rule in terms of 'once-and-for-all' settlement for personal injury claims, structured payments and proposed prescription of guidelines for the calculation of damages. ${ }^{[3]}$

\section{The way forward}

The safe delivery of babies is a benefit prioritised by politicians and society alike. ${ }^{[9,10]}$ Given current trends, it is nevertheless conceivable that soon even those willing to pay for private services may struggle to find access to high-quality obstetric care because of scarcity of qualified staff (similar to specialised paediatric neurosurgery, which is no longer available in the private sector).$^{[11]}$ While important progress has been made to turn the tide in the past year, every effort aimed at creating accurate, complete and integrated health records, analysing and sharing patient outcome and satisfaction data and collaborating on and aligning patient safety and risk management programmes must be continued. Efforts to establish care centres for the disabled, irrespective of causation, through private/ public partnerships are encouraged. On the legal side, a zero-tolerance policy for vexatious claims and plaintiff attorneys chancing their luck is called for.

\section{Bettina Taylor}

Risk specialist, EthiQal/Constantia Insurance (Pty) Ltd, Cape Town, South Africa bettinat@constantiagroup.co.za
Johannes van Waart

Obstetrician, gynaecologist and fertility specialist, private practice, Stellenbosch, South Africa; president, South African Society of Obstetricians and Gynaecologists; and founder of the BetterObs Programme

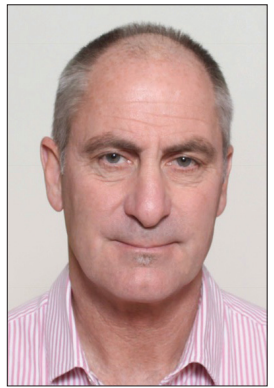

\section{Shivani Ranchod}

Senior Lecturer, Actuarial Science, Faculty of Commerce, University of Cape Town, South Africa

\section{Allan Taylor}

Head of Clinical Unit, Department of Neurosurgery, Groote Schuur Hospital, Cape Town, South Africa; president, Society of Neurosurgeons of South Africa; and president, Federation of South African Surgical Societies
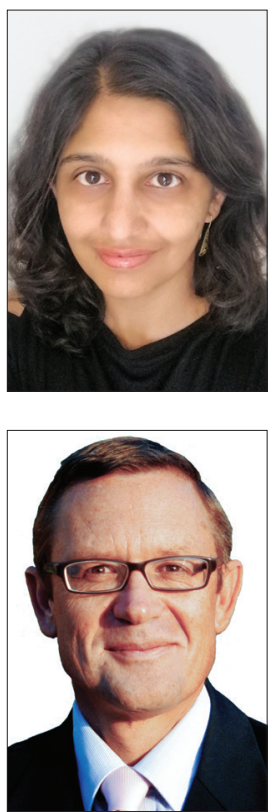

1. Howarth G, Hallinan E. Challenging the cost of medical negligence. S Afr Med J 2016;106(2):141-142. https://doi.org/10.7196/SAMJ.2016.v106i2.10408

2. Oosthuizen WT, Carstens PA. Medical malpractice: The extent, consequences and causes of the problem. Journal of Contemporary Roman-Dutch Law. https://ssrn.com/abstract=2693960 (accessed 11 February 2018).

3. South African Law Reform Commission. Issue paper 33. Project 141. Medico-legal claims. 20 May 2017. www.lssa.org.za/upload/SALRC\%20ip33_pri141_Medico-legal.pdf (accessed 11 February 2018). 2017.www.lssa.org.za/upload/__oll Rice B. How I pick the doctors I'll sue. Med Econ 2004;81(20 August):54. http://medicaleconomics. modernmedicine.com/medical-economics/news/clinical/obstetrics-gynecology-womens-health/ how-i-pick-doctors-ill-sue (accessed 11 February 2018).

. Blecher M, Daven J, Kollipara A, Maharaj Y, Mansfelder A, Gaarekwe O. Health spending at a time of low economic growth and fiscal constraints. In: Padarath A, Barron P, eds. South African Health Review 2017. Durban: Health Systems Trust, 2017. http://www.hst.org.za/publications/South\%20 African\%20Health\%20Reviews/HST\%20SAHR\%202017\%20Web\%20Version.pdf (accessed 11 February 2018).

6. Roytowski D, Smith TR, Fieggen AG, Taylor A. Impressions of defensive medical practice and medical litigation among South African neurosurgeons. S Afr Med J 2014;104(11):736-738. https://doi. org/10.7196/SAMJ.8336

7. Clark SL, Belfort MA, Byrum SL, et al. Improved outcomes, fewer cesarian deliveries, and reduced litigation: Results of a new paradigm in patient safety. Am J Obstet Gynaecol 2008;199(2):105.el-105. e7. https://doi.org/10.1016/.j.ajog.2008.02.031

8. BetterObs Programme. https://www.sasog.co.za/NewsEvents/BetterObswebpage (accessed 27 December 2017).

9. National Department of Health, South Africa. Strategic Plan 2014/15 to 2018/19. https://www.health-e. org.za/wp-content/uploads/2014/08/SA-DoH-Strategic-Plan-2014-to-2019.pdf (accessed 11 February org.za/wp-content/uploads/2014/08/SA-DoH-Strategic-Plan-2014-to-2019.pdf (accessed 11 February 2018)

10. Broomberg J. Consultative Investigation into Low Income Medical Schemes: Final Report. Pretoria: Council for Medical Schemes, 2006. https://www.medicalschemes.com/Publications.aspx (accessed 11 February 2018)

11. Howarth G, Goolab B, Dunne R, et al. Public somnambulism: A general lack of awareness of the consequences of increasing medical negligence litigation. S Afr Med J 2014;104(11):752-753. https:// doi.org/10.7196/SAMJ.8568 